\title{
Inorganic-organic hybrid membranes with anhydrous proton conduction prepared from 3-aminopropyltriethoxysilane and sulfuric acid by the sol-gel method
}

Teruaki Tezuka ${ }^{1,2}$, Kiyoharu Tadanaga ${ }^{1}$, Akitoshi Hayashi ${ }^{1}$, and Masahiro Tatsumisago ${ }^{1}$

${ }^{1}$ Department of Applied Chemistry, Graduate School of Engineering, Osaka Prefecture University, Sakai, Osaka 599-8531, Japan

${ }^{2}$ JSPS Research Fellow

\section{$\underline{\text { Supporting Information }}$}

Figure $\mathrm{S} 1$ shows DTA-TG curves of the PAPS membrane and the PAPS-HSO ${ }_{4}$ membrane. In the case of the PAPS membranes, exothermic peak accompanied with weight loss is observed at $400{ }^{\circ} \mathrm{C}$, corresponding to combustion of organic moieties. For the PAPS- $\mathrm{HSO}_{4}$ membranes, endothermic peak with weight loss is observed at around $300{ }^{\circ} \mathrm{C}$. The endothermic peaks must be due to the decomposition of $\mathrm{HSO}_{4}{ }^{-}$anion. Gradual weight loss after endothermic peaks is caused by the decomposition of residual organic moieties. Therefore, the PAPS-HSO 4 membranes were found to be thermally stable up to $300{ }^{\circ} \mathrm{C}$.

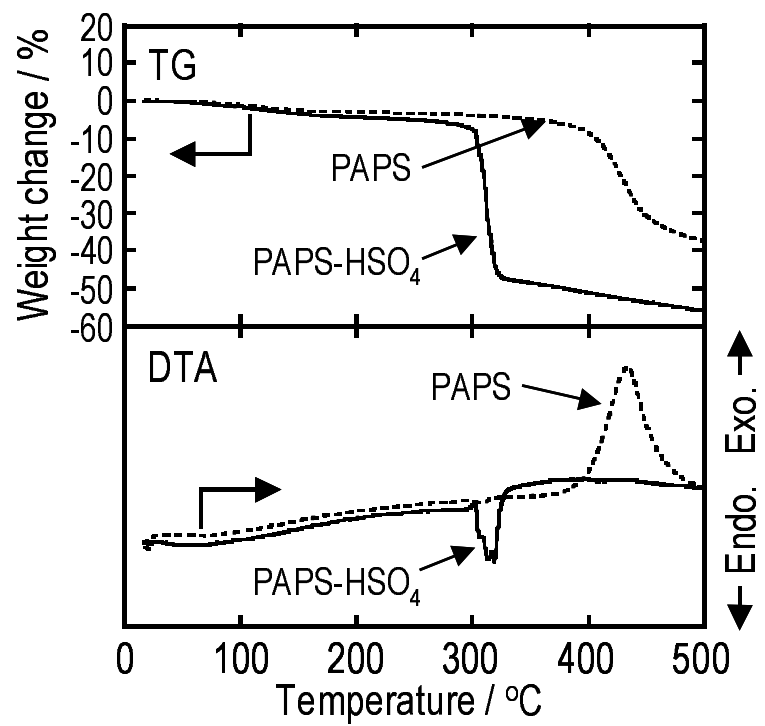

Figure S1. DTA-TG curves of the PAPS membrane and the PAPS-HSO ${ }_{4}$ membrane. 